\title{
Quince cuentos jocosos
}

MAXIME CHEvalier

\section{RESUMEN}

Aunque los cuentos tradicionales de carácter jocoso representan una parte esencial de la narración oral, conocemos mal su historia y su geografía. Con frecuencia nos contentamos con calificarlos de chistes o facecias. Conviene evidenciar el carácter tradicional que presentan gran cantidad de ellos, fenómeno que van destacando de manera cada día más clara los trabajos de una pléyade de investigadores. Los apuntes que se leen a continuación son un simple aporte a esta tarea colectiva.

Palabras clave: Folklore, Cuento, Literatura, España.

\section{SUMMARY}

Although traditional tales of a jocose quality are an essential component of oral tradition, little is known about their history and geography. People often dismiss them as jokes or facetiae. Yet it is important to evince the traditional quality of many of them, as an incresingly large number of renowned scholars point out every day. The notes presented here are but a modest contribution to this collective undertaking.

Key words: Folklore, Tale, Literature, Spain.

Circulan en la tradición oral española (y europea) crecida cantidad de cuentos jocosos. Primero los que solemos ubicar en esta categoría ("chistes y anécdotas"). Luego la casi totalidad de los cuentos de animales. Porque bajo nuestros climas los cuentos de animales han dejado hace tiempo de proponer enseñanzas morales (suponiendo que cuidaran de hacerlo en edades remotas) para convertirse en puros relatos chistosos: véanse como botones de muestra las versiones de El cuervo y la zorra que recogen Julio Camarena (1984: n. $\left.{ }^{\circ} 10\right)$ y Carlos González Sanz (1996: n. ${ }^{\text {ss }}$ 1112). Además también caen dentro de la esfera de los jocosos buena parte

RDTP, LVII, 2 (2002): 121-138 
de los llamados "cuentos románticos", que son frecuentemente -en España por lo menos- puras demostraciones de agudeza (acertijos, enigmas, engaños). Si recordamos por fin que los cuentos jocosos no exigen un narrador de dotes excepcionales, concluiremos que los llamados achistes y anécdotas" forman parte esencial de la narración oral — verdad que han oscurecido los devotos de Bajtín, exclusivamente apegados a los cuentos maravillosos.

Con ser tan difundidos estos cuentos en la tradición europea, conocemos mal su vida histórica y su expansión geográfica. (Notable excepción a esta regla representan los cuentos de animales, pacientemente estudiados por generaciones de medievalistas). En especial las huellas que dejaron los cuentos jocosos en los textos de la Europa renacentista y barroca han pasado frecuentemente desapercibidas. Esta carencia se ha de achacar a varios motivos. Ante todo, dificultó una posible investigación la ignorancia de los lectores: todos conocerían a través de los hermanos Grimm o de Perrault un elenco clásico de los cuentos maravillosos, pero muy pocos tendrían idea concreta del acervo de los jocosos tradicionales. Además la educación de los mismos lectores (unos lectores forzosamente eruditos) les inclinaba a privilegiar las fuentes escritas, haciendo caso omiso de unas posibles fuentes orales: basta examinar las ediciones más autorizadas de los Cuentos de La Fontaine para convencerse de esta realidad. Por último, conviene reconocer que los cuentos jocosos asoman con frecuencia en los textos en forma de alusiones, alusiones transparentes para unos, indescifrables para otros.

Consecuencia lógica de nuestras ignorancias es nuestra incapacidad para trazar genealogías y mapas. Consecuencia de esta incapacidad es la definición perezosa de estos cuentos como chistes, anécdotas o facecias. Conviene esforzarnos por evidenciar el carácter tradicional que presentan razonable cantidad de ellos, confiriéndoles así el estatuto que les corresponde.

En los veinte años pasados han progresado en forma espectacular nuestros conocimientos en la materia, gracias a los trabajos de un grupo nutrido de investigadores. Los apuntes que se leerán a continuación son un simple aporte a esta tarea colectiva.

1. LOS POLVOS DE ADIVINAR

(Tipo $910 \mathrm{G}$ )

Es burla que se puede dar entre amigos o conocidos (Arguijo 1979: n. ${ }^{\circ}$ 627): 
Un caballero, mozo de buen gusto, queriendo hacer una burla a tres o cuatro amigos suyos, les dijo lo que se sigue, en Granada:

-El diablo son estos italianos. Pasando ayer por la plaza, estaba un charlatán de ellos dando voces: "¿Quién compra polvos de adivinar?» Pregunté lo que quería decir, y respondióme que eran unos polvos que, en tomándolos uno por la boca, adivinaba al punto alguna cosa. Vi que los daba a cuarto cada papel; compré un real de ellos, tomé allí uno y al punto adiviné que mi hermano venía anoche desde Madrid, sin haber tenido aviso de que partía de allá; y no pasaron dos horas cuando entró por las puertas de mi casa. Tomé otro esta mañana, y adiviné que Lorencillo, mi negro, había parecido, y no pasó un cuarto de hora cuando unos cuadrilleros de la Hermandad me lo trujeron maniatado.

Los amigos, maravillados del caso, le rogaron que diese a cada uno su papelillo, pues que había comprado tantos. Respondió:

-Aquí los traigo. Hagamos juntos la prueba, tomándolos todos a un mismo tiempo, y veréis maravillas.

Traía él entre los otros uno señalado que tomó para sí, y repartió los demás, y echándoselos todos en la boca, comenzó a escupirlos cada uno, diciendo:

- Juro a Dios que es mierda molida esto, por Nuestro Señor!

Dijo entonces el socarrón dando voces:

-iVive Dios que han hecho efecto los polvillos! Todos han adivinado lo que son. Sin duda son mierda seca. ¡Válgate el diablo el italiano! También yo en tomándolos adiviné lo que eran.

Se repite la escena en el Bureo de las Musas del Turia de Jacinto Alonso Maluenda ([1631] 1951: 37-38) y en la Tercera parte de Guzmán de Alfarache de Félix Machado de Silva (1927: 75-76). Poggio (1964: n. ${ }^{\text {os }} 164-$ 165) atribuye la burla al ingenio de Gonnela.

También puede dirigirse la burla a unas colectividades: es mala pasada que juega Eulenspiegel (1995: n. ${ }^{\circ}$ 35) a los judíos de Francfort, y Charlotte Melson, femme savante del siglo XVII francés, a unos boticarios parisienses (Tallemant des Réaux 1967: II, 845-846).

Variante del cuento es la historia del pueblo que decide adquirir la verdad. Véase una versión española del Siglo de Oro (Pinheiro da Veiga 1989: 231):

El rey de Portugal, faltando la verdad en su reino, mandó por ella a un embajador y diéronle en Castilla un servicio muy empapelado, diciendo que le llevasen, que era muy sutil. Abriéndole delante del rey, dijo él:

-Por vida mía, reina, que huele a mierda.

El embajador metió la mano y dijo:

-Juro a Dios que es verdad.

Y así quedó la verdad en Portugal.

En la tradición española moderna el relato ha venido a ser cuentopulla que se aplica a varios pueblos: verdad de Olías (Cuentos y chascarrillos andaluces 1896: 234-235), verdad de Pamplona (Iribarren 1974: 2930), verdad de Lleida (Amades 1974: $n .^{\text {os }}$ 653-654), etc. 
Conclusión: Los polvos de adivinar fue cuento tradicional en gran parte de Europa (Alemania, España, Francia, Italia). Sigue viviendo en la tradición española.

2. UNA DECLARACIÓN DE AMOR

(Tipo 923, variante)

Aparece el cuento en la jornada tercera de la comedia El paraíso de Laura y florestas de amor, comedia de autor desconocido (Lope de Vega, Obras, Acad. N., VIII: 386 b-387 a):

\section{CAMARÓN}

Sólo por ti me pesara temer algún mal suceso, que te quiero mucho más que al más lindo dar de cuerpo.

\section{FENISA}

¿Hay mayor puerco que tú? ¿A eso me comparas, necio?

\section{CAMARÓN}

No lo tengas a desaire hasta entender el misterio de este concepto, Fenisa, $\mathrm{y}$ ahora contarte quiero que esto mismo dijo un novio a su esposa, y al momento quedó con desdén extraño; y estando un día comiendo, le dio un apretón de tripas; levantarse quiso luego; él la detuvo gran rato; fuese en fin a un aposento con los colores mudados, salió después, y el tal dueño la dijo: "Agora sabrás el fondo de mi requiebro". Ella le replicó entonces "Ya lo he visto, y agradezco que los tengas tan sabido [sic] que hayas pasado por ellom.

\section{FENISA}

Eso mismo digo yo.

\section{CAMARÓN}

A fe que te vengas presto. 
Una versión larguísima del mismo cuento se lee en Le moyen de parvenir de Béroalde de Verville ([1610] 1896: II, 100-101).

Recogen el cuento Aurelio M. Espinosa (1946: $n^{\circ}$ 108) y Nieves Gómez López (1998: n. $\left.{ }^{\circ} 88\right)$.

El cuento pertenecía al folklore español y al folklore francés del siglo xvII. Sigue viviendo en la tradición española.

\section{CRISTO ¿VIVO O MUERTO?}

El cuento, recogido por Nicolas de Troyes (1970: n. ${ }^{\circ} 34$ ), entra en la recopilación de Juan de Arguijo (1979: n. ${ }^{\circ}$ 102):

Mandaron hacer unos labradores de Lucena a un escultor de Córdoba un Cristo para su cofradía. Preguntábales el artífice si había de ser muerto o vivo. No supieron resolverse, y en caso de duda, le dijeron que lo hiciese vivo, que si así no contentase, allá lo matarían.

Aunque lo pudieran tomar el español y el francés de la colección de Poggio (1964: n. ${ }^{\circ}$ 12), la riqueza y la variedad que ofrece la tradición española moderna - la tradición aragonesa en especial- demuestran sin dejar lugar a dudas que estamos en presencia de un cuento plenamente tradicional. Conozco siete versiones recogidas en los siglos XIX y XX: Joan Amades (1974: n. ${ }^{\circ}$ 553), Benito Más (1925: 425), Pedro Felipe Monlau (1862: 329-330) (dos versiones), D.V., Cuentos aragoneses (Domínguez Lasierra 1979: I, 120-121); "Tío Jorge", Cuentos de las cinco villas (Domínguez Lasierra 1979: 126-127); Teodoro Gascón Baquero, Historietas baturras (Domínguez Lasierra 1979: I, 144). En las versiones de Juan de Arguijo, Amades, D.V. y Monlau 2 el inocente campesino ha de escoger entre un Cristo agonizante y un Cristo muerto; en la versión de Benito Más entre un Cristo crucificado y un Cristo atado a la columna; en la versión de Monlau 1 entre un San Lorenzo vivo y un San Lorenzo muerto; en la versión de "Tío Jorge" entre un San Sebastián agonizante y un San Sebastián muerto; en la versión de Gascón Baquero entre un San Bartolomé vivo y un San Bartolomé muerto.

El cuento pertenece al folklore de España y Francia en la época renacentista y barroca. Lo conserva la tradición española moderna.

4. ¿VISTEIS POR ALLÁ MI HACA?

(Tipo 1355 B)

Es cuento tradicional que apunta el recopilador de los Dichos graciosos de españoles notables ( $\mathrm{n} .^{\circ}$ 86), atribuyendo el papel del tonto a un truhán: 
Velasquillo, truhán del rey don Fernando el Católico, había perdido una haca y no la podía hallar. Subióse acaso encima de un árbol de donde se descubría el rey y la reina que estaban burlando, y diciéndole el rey que le mostrase las piernas, la reina lo hizo, y dijo el rey:

-Paréceme, señora, que veo a todo el mundo.

Oyéndolo Velasquillo, dijo desde el árbol donde estaba:

-Decid: ¿vistes por allá mi haca?

Lope de Vega recuerda el cuento en dos comedias suyas: Los comendadores de Córdoba, II (BAE, 215: 26 a) y Amar sin saber a quién, II (Acad. N., XI: 306 b).

En Francia lo aprovecha el autor de las Cent nouvelles nouvelles (1965: n. ${ }^{\circ}$ 12), y después de él La Fontaine (1961: "Le villageois qui cherche son veau").

Tardó el cuento en entrar en las colecciones impresas: debió de asustar a los investigadores su tranquilo erotismo. La primera versión oral que leí en letras de molde fue la que imprimió Ana M. ${ }^{a}$ Cano González (1989: n. ${ }^{\circ}$ 19). Luego vinieron otras: véanse en especial las cuatro versiones que trae la colección de Jesús Suárez López (1998: n. ${ }^{\circ}$ 62). En Francia únicamente lo leí en una colección impresa años después de la muerte de su autor (Perbosc 1987: 43-44).

También vivía el cuento en la tradición alemana del siglo xvi. En efecto lo trae, como anécdota, la crónica de la familia bávara de los Zimmern, crónica redactada por el barón W.W. von Zimmern (1485-1575), por su sobrino el conde Froben Christoph y el secretario de éste. (No he podido manejar el texto de dicha crónica, que únicamente conozco a través de un ensayo de Ernst Jünger 1982: 212-214).

Cuenta la crónica que a cierto pastorcico se le escaparon dos terneros. El muchacho, asustadísimo, fue a esconderse bajo la estufa del convento de Wald. Ocurrió que a uno de los monjes le dio por retozar con la cocinera en el mismo banco de la estufa. Al poco tiempo exclamó entusiasmado: «AAquí veo el mundo y todo lo que contiene!» Replicó el muchacho: "iA ver si me descubres los terneros!".

Hacia 1500-1600 el cuento 1355 B pertenece al folklore de Alemania, España y Francia. Aún vivía en la tradición francesa hacia 1900. Hoy sigue viviendo en la tradición española. 


\title{
5. DOS VECES VEINTE SON CUARENTA
}

\section{(Tipo $1362 \mathrm{~B}^{*}$ )}

El cura de Brou, en vez de tener ama de cincuenta años, empleaba dos muchachas, una de veinte y otra de treinta años (Des Périers [1558] 1965: n. ${ }^{\circ}$ 34).

Aparece el cuento en una comedia de Vélez de Guevara, Rojas Zorrilla y Mira de Amescua, El pleito que tuvo el diablo con el cura de Madrilejos [suelta BNM, s.f., T6.376], jornada II:

\section{MARINA}

\author{
A Madrilejos \\ con aquella carga voy \\ de leña, para su cura, \\ de quien, aunque moza soy, \\ soy ama desde este día, \\ porque él viendo que es razón \\ que un ama de un cura tenga \\ cincuenta años, la trocó \\ en menudos, y así tiene \\ de hasta veinte y cinco dos.
}

Lo recuerda Diego de Torres Villarroel (1966: n.ำ 161, p. 207):

Aquellos curas bravíos, sacerdotes casados que mantienen en los pueblos y aldeas cortas cincuenta años de criada en dos tomos.

Es cuento tradicional en Francia: lo conozco desde niño. Sorprendentemente afirman mis amigos españoles que no lo tienen recogido. Confío que algún día se ha de llenar este hueco. (En efecto aparece el cuento en una colección peninsular: Bllat Colrat. I 1997: n. $\left.{ }^{\circ} 309\right)$.

6. EL TOCINO DEL PARAÍSO

(Tipo 1516)

Se trasluce este cuento en el refranero áureo. Lo apunta Hernán Núñez (1555: fol. 37 ro):

El tocino del paraíso, para el casado, y no arrepiso. 
Lo aclaran Juan de Mal Lara y Correas:

El tocino del paraíso, para el casado no arrepiso.

Fingen las viejas que hay un tocino del paraíso, que comen de él los casados que no se arrepienten, cuando van allá, y que hasta agora está por probar. (Mal Lara 1996: 370).

El tocino del paraíso, para el casado, y no arrepiso.

Fingen que hay un tocino colgado en el paraíso para los casados que no se arrepienten, y que está por empezar; con que dan a entender que no hay ningún casado que no se haya arrepentido una vez u otra (Correas [1627] 1967: 111 b).

Recuerda el dicho, en forma confusa, Mateo Alemán (1967: II, III, 5). Siguió viviendo el cuento en la tradición española: lo reproduce Fernán Caballero en La Gaviota (BAE: 136, p. 53 b) y aparece en la colección de relatos tradicionales de Emilio Pendás ([1939] 2000: n.․ 64). Sobre este relato véase ahora Suárez López (e. p.).

Vivía en la tradición oral francesa del siglo XVII según documentan La Fontaine y Tallemant des Réaux:

Outre la vigne qu'on dit que M. L'Archevêque doit donner à celui qui au bout de l'an n'aura point de repentir de s'être marié... (Tallemant 1967: II, 829).

L'an révolu, ce couple si charmant

Toujours d'accord, de plus en plus s'aimant

(Vous eussiez dit la première journée)

Se promettait la vigne de l'abbé...

(La Fontaine 1961: "Les aveux indiscrets").

7. Así PAGA EL DIABLO

(Tipo $1645 \mathrm{~B}$ )

Vivía el cuento en la tradición española y en la tradición francesa de los siglos XVI y XVII:

A este mismo propósito me acuerdo oír decir y afirmar en mi niñez que poniendo uno una noche a los apóstoles de piedra que están a la Puerta del Perdón de la Santa Iglesia de Toledo, a cada uno una candelilla de cera por su devoción [...], puso también una candelilla que le quedaba al demonio que está allí atado a los pies de San Bartolomé. Y que esa noche el que puso las candelillas estando en su cama soñó que el demonio venía a él y le daba gracias por la candelilla que a él le puso y le decía:

- Anda acá, llevarte he donde halles un tesoro.

Y que le llevaba a un campo, y le decía:

-Aquí le hallarás. Cágate ahí encima porque aciertes donde está. 
Y que en esto había recordado, y se había hallado todo cagado en la cama. Y cierto no es esto fábula, porque conocí al hombre a quien dicen que aconteció, el cual dicen que así lo decía y afirmaba (Horozco 1994: 196-197, 441).

(Otra versión del cuento aparece en la comedia de Rojas Zorrilla, La más hidalga hermosura, II, BAE, 54, pp. 518 b-519 a).

Il y avait un pauvre paysan qui avait quantité d'enfants, et n'avait pas de pain pour leur donner pour lors que la famine pressait. Une nuit, s'étant endormi de tristesse, il songea qu'il trouva le Diable qui le consola et lui dit que, s'il voulait, il lui donnerait de quoi bailler à dîner à son menu peuple, et là-dessus le mena en une forêt obscure, où il lui montra de grands sacs pleins de farine. Le paysan, ébahi et aise, dit:

-Mais comment trouverai-je ce lieu si j'en parts?

Le Diable lui dit:

- Chie auprès pour le remarquer.

Le triste pauvre homme s'efforça et fianta dans le lit plus que six ladres constipés ne feraient par un clystère renforcé de quadruple dose de fine bénédicte. A son réveil il trouva le bran en quoi s'était toute réduite cette diabolique farine (Béroalde de Verville [1610] 1986: I, 219-220).

Sigue viviendo el cuento en la tradición española moderna (De Llano 1975: n. ${ }^{\circ}$ 59). Vivía sin duda en la tradición oral francesa del siglo XIX (véase el relato de la Condesa de Ségur 1930: XI).

\section{LA INTENCIÓN BASTA}

(Tipo 1804)

El cuento pertenece a las tradiciones española y francesa de los siglos XVI y XVII. Lo copia Cristóbal de Villalón en El Scholástico (1967: 217):

Semejante fue a este donaire el que aconteció a un cura con un su feligrés, que viniéndose a confesar, dijo que había hurtado un cabrito a su vecino, y que se le volvió luego arrepentido, y cree que pecó, pues tuvo voluntad. Dijo el cura:

- Hermano, vos pecastes como si le comiéredes, porque voluntas pro facto reputatur, que quiere decir que la voluntad se reputa como si fuese hecho: dadme un real y restituirse le he yo a vuestro vecino, porque satisfagáis para vuestro pecado.

El penitente sacó de la bolsa un real y tendió la mano para dársele al cura, y cuando el cura le iba a tomar, huyó la mano el penitente y díjole:

- Señor, así agora en la restitución que la voluntad se reputará por el hecho, y así vos, señor, restituid con vuestra voluntad por mí.

En Francia figura entre los cuentos de Nicolas de Troyes (1970: n. ${ }^{\circ}$ 51), y verosímilmente inspiró a La Fontaine el cuento titulado "Le cas de conscience". 
La tradición española moderna documenta ampliamente el cuento (véase Camarena 1991: n. ${ }^{\circ}$ 262).

Varios estudiosos, apegados incondicionalmente a las fuentes escritas, confunden este cuento con la historia de Lamia indemnizada por el sonido del dinero (Plutarco, Vida de Demetrio).

9. El testamento Del ASNO

(Tipo 1842)

El dueño de un asno suplica que se entierre el animal en el camposanto (o en la iglesia). Se irrita el cura (el obispo). Se aplaca después de recibir unos escudos en concepto de legado del inteligente animal.

El cuento aparece en un fabliau (Montaiglon-Raynaud 1872-1890: $\mathrm{n}^{\circ}$ 82), entre las Facetiae de Poggio (1954: $\mathrm{n}^{\circ} 35$ ), las Cent nouvelles nouvelles (1965: $\mathrm{n}^{\circ}$ 96) y los Cuentos de Juan de Arguijo (1979: $\mathrm{n}^{\circ}$ 690).

La tradición española parece conservar el cuento, aunque sin gran actividad (Fernán Caballero, Las noches de invierno en las gañanias: n. ${ }^{\circ}$ 6).

10. El MUCHACHO DE LA COLA DE LOBO

(Tipo 1875)

Prisionero de un tonel, un muchacho consigue agarrarse de la cola de un lobo. Huye a todo correr el animal despavorido. Se rompe el tonel, escapa el lobo, sale ileso el muchacho.

Este cuento de mentiras pertenece a las tradiciones española y francesa del siglo XVII: aparece en El Menandro de Matías de los Reyes (1909 [1636]: 192-193) y en Les aventures $d u$ baron de Faeneste de Agrippa d'Aubigné (1855 [1617-1630]: III, 7).

Siguió viviendo en ambas tradiciones (Amades 1974: $\mathrm{n}^{\circ}$ 530; Mistral 1929: IV).

\section{LA COL Y LA CALDERA \\ (Tipo 1920 A)}

El cuento circula oralmente en la España del siglo XVI. Véase la versión de Luis de Pinedo (Libro de chistes, 112):

En Monzón de Campos estaba un hidalgo que había venido de las Indias, y un día, contando cosas de aquellas partes a otros vecinos, dijo: 
-Yo vi una berza en las Indias, tan grande que a la sombra de ella podían estar trescientos de a caballo sin que les diese ningún sol.

Dijo otro, criado del marqués de Poza:

-No lo tengo en mucho, porque yo vi en un lugar de Vizcaya que hacían una caldera en la cual martillaban doscientos hombres, y había tanta distancia del uno al otro que las martilladas del uno no oía el otro.

Maravillándose mucho el indiano, dijo:

- Señor ¿para qué era esa caldera?

Respondió el otro:

- Señor, para cocer esa berza que acabáis de decir.

En Francia también circula el cuento en la misma época: Nicolas de Troyes (1970: n. ${ }^{\circ}$ 49) y La Fontaine (Fables, IX, 1).

Sigue viviendo el relato en la tradición española (véanse, por ejemplo, Espinosa 1987-1988: n. ${ }^{\circ} 440$; Amades 1974: n. ${ }^{\circ}$ 76; Contos populares da provincia de Lugo 1972: n. ${ }^{\circ} 173$ ).

Creo poder afirmar que el cuento aún vivía en la tradición oral francesa hace medio siglo.

\section{2. ¡NO LE ARRIMEN AL MANZANO!}

(No clasificado por Aarne-Thompson)

El cuento pertenece a la tradición oral áurea. Lo copian Juan de Mal Lara (1996: 314-315) y Correas ([1627] 1967: 71 b). Reproduzco la segunda versión, más breve:

Apartalde del manzano, no sea lo de antaño

...Es el cuento que un hortelano se fingió muerto para tentar y saber lo que tenía en su mujer; y llevándole a enterrar, descansaron en el camino y pusiéronle junto a un manzano; allí se asió de un ramo y volvió en sí de la muerte fingida. Otra vez, de ahí a un año, murióse de veras, y llevándole a enterrar, avisó la mujer que le apartasen del manzano, no fuese lo de antaño, como si el manzano tuviera virtudes de dar vida.

También pertenece a la tradición francesa en el siglo XVII: lo traen Tallemant des Réaux (1967: I, 178) y la Menagiana (1715: I, 321).

Sigue viviendo en la tradición española: véanse las copiosas referencias que apuntan Julio Camarena (1991: n. ${ }^{\circ}$ 272), y José Luis Agúndez en Manuel M. ${ }^{a}$ de Santa Ana (1999: 196).

13. LAS PREGUNTAS DE LA VENTERA

(No clasificado por Aarne-Thompson)

El cuento era tradicional en la España áurea según documenta la púdica versión que ofrece Joan Timoneda (1990: núm. 25): 
Yendo tres de compañía, un capitán, y un recuero, y un rufián, allegaron a una venta que era de una viuda muy truhanera. Preguntáronle si había algo que cenar. Díjoles que no había otra cosa, sino un par de perdigones, pero que los cenaría con ella aquel que le declarase tres preguntas. Contentos, preguntóles qué sombra había mejor, y vista, y ruido, en esta mundana vida. Respondió el capitán:

- Sombra de tienda de campo, vista de españoles y ruido de atambores.

Respondió el recuero:

- Sombra de mesón, vista de poblado, ruido de acémilas.

Respondió el rufián:

-Sombra de pabellón, vista de gentil mujer, ruido de colchones.

Dijo ella:

-Vos cenaréis conmigo los perdigones.

También era tradicional en la Francia del siglo Xvi: véanse las versiones, más crudas y sin ninguna duda más cercanas a la tradición oral, que ofrecen Rabelais (1959, Pantagruel: XXVII) y Nicolas de Troyes (1970: n. $\left.{ }^{\circ} 12\right)$.

El cuento sigue viviendo en la tradición española según evidencian las versiones recogidas por José Luis Puerto (1995: n. ${ }^{\circ}$ 62) y por Arturo Martín Criado (1995), así como la que recogió Julio Camarena en Madrid:

Era una vez, en un cuartel, que había una mujer impresionante. Estaban todos los del cuartel detrás de ella, y los tres que más, pues eran un capitán, el capellán y un soldadito. Entonces ella decide una vez quedar con los tres. Queda con los tres, cada uno creído que sólo había quedao con él, y cuando llegan a la reunión, pues se encuentran que estaban los tres. Entonces ella coge y dice:

- Bueno, entonces a ver: yo me acuesto con el que me diga qué es potente, qué es brillante y el son de los sones.

Entonces empieza el capitán:

- Potentes, mis ejércitos; brillante, mi sable; y el son de los sones, mis tambores.

Llega el capellán y dice:

- Bah, eso no es nada. Potente, mi cáliz; brillante, mi patena; y el son de los sones, las campanas de la iglesia.

Llega el soldadito y dice:

- Potente, mi polla; brillante, tu chumino; y el son de los sones, tus pechos y mis cojones.

Y se quedó con él, claro.

14. EL DUENDE CARIÑOSO

(no clasificado por Aarne-Thompson)

Es cuento bien documentado en el siglo Xvil, puesto que lo reproducen tres dramaturgos: Álvaro Cubillo de Aragón (s. f.: fol. 8); Juan de Matos 
Fragoso (El Job de las mujeres, Comedias escogidas de los mejores ingenios de España, IX: 307 b-308 a) y Gabriel del Corral (La trompeta del juicio, Comedias escogidas de los mejores ingenios de España, XXXI: 285). Véase el texto de Álvaro Cubillo de Aragón:

\title{
GALINDO
}

\author{
Va de cuento: había en Madrid \\ un cortesano discreto \\ a quien daba malos ratos \\ un duende en su casa, y viendo \\ que exorcismos ni conjuros \\ no eran bastante remedio, \\ como entonces se mudase \\ la Corte, acordó resuelto \\ mudarse a Valladolid. \\ Y estando hecho el apresto, \\ toda la ropa liada, \\ cargados todos los tercios, \\ vio bajar por la escalera \\ un frailecillo pequeño \\ con las alforjas al hombro. \\ Y él, espantado de verlo \\ (si bien conoció quién era) \\ le dijo: "Padre, ¿qué es esto? \\ ¿Dónde bueno es el viaje? \\ $Y$ respondió el frailezuelo: \\ "Pues ¿no nos mudamos? Voy \\ siguiendo el hato, y siguiendo \\ la Corte a Valladolid". \\ Admirado el caballero, \\ suspendió de su viaje \\ el ya comenzado intento, \\ diciendo: "Si con nosotros \\ se va el padre reverendo, \\ duende acá, duende acullá, \\ en Madrid sufrirlo quiero".
}

De "cuentecillo de mucho arraigo en España" lo califica Julio Caro Baroja (1984: 141). En efecto, lo traen Fernán Caballero (Elía, o la España treinta años ha, BAE, 138: 35 b); Constantino Cabal (1983: 230); Francisco Rodríguez Marín (1941: 125 a); Aurelio M. Espinosa, hijo (1987-1988: n. ${ }^{\circ} 180$ ); Jesús Suárez López (1998: n. ${ }^{\circ} 33$ ), entre otros. (Véase también la tradición de Guadalajara recogida por José R. López de los Mozos 1997).

El cuento también pertenece a la tradición oral alemana: véase Jacob y Wilhelm Grimm (2000: $\mathrm{n}^{\circ}$ 72) (así como el sugestivo comentario de mi 
admirado amigo José Manuel Pedrosa, ibid:: 33-34). También a la tradición oral danesa, según declaró Andersen a Heine (Heine 1979: 48).

15. Ya QUe el ÁNIMA SAlió del PURgatorio... (no clasificado por Aarne-Thompson)

El cuento aparece por primera vez, que yo sepa, en la Apologie pour Hérodote de Henri Estienne ([1566] 1879: II, 366):

Un autre en France joua d'un autre tour: car quand on lui vint demander paiement pour les messes qui avaient délivré de purgatoire une certaine âme, interrogea les prêtres si depuis que les âmes étaient une fois sorties de purgatoire, elles n'étaient plus en danger d'y retourner; et lui ayant été répondu que non:

Il n'est pas donc besoin - dit-il- que je vous donne de l'argent pour cette-ci, qui est ja délivrée et mise en sauveté; mais il le vaut mieux garder pour une autre qui y sera encore détenue.

Este relato, que parece hacer eco a la célebre afirmación del dominico Tetzel ("En cuanto suena la moneda en el cepillo, vuela el ánima fuera del Purgatorion), no sorprende bajo la pluma del calvinista Henri Estienne.

La sorpresa surge en el siglo XVII cuando dos viajeros franceses atribuyen el chiste al conde de Villamediana: Antonio de Brunel, Diario del viaje a España (1665) (VV. AA. 1952-1962: II, 417 b) y Madame d'Aulnoy, Relación del viaje de España (1679) (ibid.: 980). (También sale el cuentecillo en el Viaje a España del caballero San Gervasio, en ibid.: III, 1257 b). Mantiene esta atribución dos siglos más tarde Hartzenbusch en su comedia Vida por la bonra (1858: III).

Según apuntan Montserrat Amores (1997: n. ${ }^{\circ}$ 193) y José Luis Agúndez (Santa Ana 1999: 202), reproducen el chiste, sin atribuirle a ninguna persona concreta, la Floresta española de Asensio ( $n^{\circ} 1278$ ), Fernán Caballero en La Gaviota (BAE, 136: 24 b-25 a) y Luis León Domínguez (s.f.: 69-70).

El cuento debió de hacerse tradicional, hasta cierto punto, en la España áurea. Se me escapan los motivos de la presencia de Villamediana en esta historia.

\section{BIBLIOGRAFÍA CITADA}

Alemán, M.. 1967. Guzmán de Alfarache, en Francisco Rico (ed.), La novela picaresca española, I. Barcelona: "Clásicos Planeta", n. 12.

AmADES, J. 1974. Folklore de Catalunya. Rondallística. Barcelona: Editorial Selecta. 
AMORES GARCÍA, M. 1997. Catálogo de cuentos folclóricos reelaborados por escritores del siglo XIX. Madrid: CSIC.

ARguijo, J. de. 1979. Cuentos. Sevilla: Diputación Provincial de Sevilla.

Aubigné, A. d'. [1617-1630] 1855. Les aventures du baron de Faeneste. París: P. Jannet. BÉROALDE DE VERVILLE, F. [1610] 1896. Le moyen de parvenir. París: Alphonse Lemerre. Bllat ColRAT. 1997. Literatura popular catalana del Baix Cinca, la Llitera i la Ribagorça. Instituto de Estudios Altoaragoneses.

CABAL, C. 1983. La mitología asturiana. Oviedo: IDEA.

CAMAREma LaUCirica, J. 1984. Cuentos tradicionales recopilados en la provincia de Ciudad Real. Ciudad Real: Instituto de Estudios Manchegos.

- 1991. Cuentos tradicionales de León. Madrid: Diputación Provincial de León y Seminario Menéndez Pidal.

CANo GonZÁlez, A. M. a . 1989. Notas de Folklore Somedán. Uviéu: Academia de la Llingua Asturiana.

CARO Baroja, J. 1984. Del viejo folklore castellano. Valladolid: Ámbito.

Cent nouvelles nouvelles (Les), Conteurs français du XVI siècle. 1965. París: Pléiade, Gallimard.

COMTESSE DE SÉGUR. 1930. Les vacances. París: Hachette.

Contos populares da provincia de Lugo. 1972. Vigo: Centro de Estudios Fingoy, Galaxia.

CORRAL, G. del. s.f. La trompeta del Juicio, Comedias escogidas de los mejores ingenios de España, XXXI.

CORREAS, G. [1627] 1967. Vocabulario de refranes y frases proverbiales. Bordeaux: Université. Ed. de Louis Combet.

CUBILlo DE ARAGÓN, Á. s.f. Entre los sueltos caballos. Suelta, s.l.

Cuentos y chascarrillos andaluces tomados de la boca del vulgo. 1896. Madrid: Librería de Fernando Fé.

DES PÉRIERS, B. [1558] 1965. Nouvelles récréations et joyeux devis, en Conteurs français du XVI siècle. París: Pléiade, Gallimard.

Dichos graciosos de españoles notables. Manuscrito de la biblioteca de Antonio Rodríguez-Moñino.

DOMÍNGUEZ LASIERRA, J. 1979. Cuentos, recontamientos y conceptillos aragoneses. I-II. Zaragoza: Librería General.

EsPINOSA, A. M. 1946. Cuentos populares españoles. Madrid: CSIC.

EsPINOSA, A. M., hijo. 1987-1988. Cuentos populares de Castilla y León. Madrid: CSIC. EstienNe, H. [1566] 1879. Apologie pour Hérodote . París: Liseux,.

FERNÁN CABALlero. Elía, o la España treinta años ha, Obras, BAE, 138.

- La Gaviota, Obras, BAE, 136.

- Las noches de invierno en las gañanías, "Colección de Escritores Castellanos", núm. 158.

GÓmEZ LÓPEZ, N. 1998. Cuentos de transmisión oral del Poniente almeriense. Almería: Ayuntamiento de Roquetas de Mar.

González SAnZ, C. 1996. Despallerofant. Castellón: Institut d'Estudis del Baix Cinca.

GRIMM, J. y Wilhelm. 2000. La mujer del musgo y otras leyendas alemanas. Oiartzun: Sendoa. Ed. de J. M. Pedrosa.

HARTZENBUSH, J. E. 1858. Vida por la honra, suelta. Madrid.

HeINE, H. 1979. De l'Allemagne. París: "Les presses d'aujourd'hui”.

HOROzCO, S. de. 1994. El libro de los proverbios glosados. I-II. Kassel: Reichenberger. 
IrIBARREN, J. M. ${ }^{3}$ 1974. Burlas y chanzas. Miscelánea festiva. Pamplona.

JÜNGER, E. 1982. L'auteur et l'écriture. I. París: Christian Bourgeois.

LA Fontaine, J. de. 1961. Contes et nouvelles en vers. Paris: Garnier frères.

LEÓN Domínguez, L. s. f. Los cuentos de Andalucía. Madrid: Editorial Voluntad.

Llano Roza DE Ampudia, A. de 1975. Cuentos asturianos. Oviedo: Delegación Provincial de Cultura.

LÓPEZ DE LOS MOZOS, J. R. 1997. "El duende Martinico de Mondéjar y los duendes de Berninches (Guadalajara)". Revista de Folklore 200: 71-72.

MACHADO DE SILVA, F. 1927. Tercera parte de Guzmán de Alfarache. Revue Hispanique 69: $1-340$.

MAL LARA, J. de. 1996. Filosofía vulgar. Madrid: Turner.

Maluenda, J. A. [1631] 1951. Bureo de las Musas del Turia. Madrid: CSIC, "Antiguos Libros Hispánicos", XVII.

MARTín CRIADO, A. 1995. "La mejor respuesta, el mejor discurso, el mejor sueño". Revista de Folklore 173: 166-168.

Matos Fragoso, J. de. El Job de las mujeres, en Comedias escogidas de los mejores ingenios de España, IX.

MAS Y PRAT, B. 1925. La tierra de María Santísima. Madrid: Biblioteca Giralda.

Menagiana ou les bons mots et remarques critiques, bistoriques, morales et d'érudition de Monsieur Ménage. 1715. París: Florentin Delaulne.

Mistral, F. 1929. Mémories et récits. París: Plon.

MONLAU Y ROCA, P. F. 1862. Las mil y una barbaridades. Madrid.

MONTAIGLON, A. de y GASTON RAYNAUD. 1872-1890. Recueil general et complet des fabliaux des XIII et XIV siècles. París.

NúNEZ, H. 1555. Refranes o proverbios en romance. Salamanca: Juan de Cánova.

Pendés TRelles, E. 2000. Cuentos populares recogidos en el penal del Puerto de Santa María (1939). Gijón: Ayuntamiento de Gijón.

PERBosc, A. 1987. L'anneau magique. Carcassonne: GARAE/HÉSIODE.

PINEDO, L. de. Libro de chistes. Madrid: BAE, 176.

PInHeIro DA VeIGA, T. 1989. Fastiginia. Valladolid: Ámbito.

PlutaRCo. 1967. Vies parallèles des hommes illustres. I. II, París: Le Club français du livre. Poggio Bracciolini, G. 1964. Facezie. Milán: Dall'Oglio.

PuerTo, J. L. 1995. Cuentos de tradición oral en la Sierra de Francia. Salamanca: Caja Salamanca y Soria.

Rabelais, F. 1959. Oeuvres. Paris: Pléiade, 1959.

REYES, M. de los. [1636] 1909. El Menandro. Madrid: "Colección Selecta de Antiguas Novelas Españolas", X.

RODRÍGUEZ MARÍN, F. 1941. Todavía 10.700 refranes más no registrados por el maestro Correas. Madrid, Imprenta "Prensa Española".

ROJAS ZORRILlA, F. de. La más bidalga bermosura, en Comedias escogidas. Madrid: BAE, 54.

SANTA ANA, M. M. de. 1999. Cuentos y romances andaluces (1844-1869). Sevilla: Junta de Andalucía.

SuÁrez LópeZ, J. 1998. Cuentos del Siglo de Oro en la tradición oral de Asturias. Gijón: Museo del Pueblo de Asturias.

- e. p. "El tocino del paraíso: una vieja costumbre inglesa, un refrán del Siglo de Oro y un cuento astur-andaluz. Revista de Filoloxía Asturiana 1.

Tallemant Des RÉAuX, G. 1967. Historiettes. París: Gallimard. 
Till Eulenspiegel (Les aventures de). 1995. París-Ginebra: Slatkine.

Timoneda, J. 1990. Buen Aviso y Portacuentos. El Sobremesa y Alivio de Caminantes. Madrid: Espasa-Calpe.

TORRes Villarroel, D. de. Visiones y visitas de Torres con don Francisco de Quevedo por la Corte. Madrid: Espasa-Calpe.

TROYES, N. de. 1970. Le grand Parangon des nouvelles nouvelles. París: Didier.

VEGA, L. de. Comedias, BAE, 1853-1860 y 1963-1972.

- Obras. Madrid: Real Academia Española (Acad. N.).

VÉlez DE Guevara, Rojas ZORRILla, MIRA DE AmEscua. s.f. El pleito que tuvo el diablo con el cura de Madrilejos, suelta, BNM T6.476, s.f.

Villalón, C. de. 1967. El Scholástico. Madrid: CSIC.

VV. AA. 1952-1962. Viajes de extranjeros por España y Portugal. Madrid: Aguilar. 